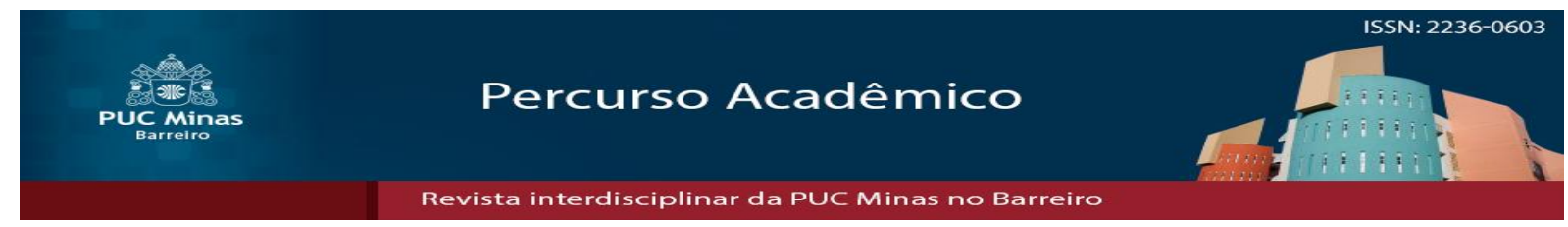

\title{
A implementação da gestão democrática na educação e o novo modelo de gestão pública
}

\section{The implementation of democratic management in education and the new model of public management}

\author{
Nelson Lambert de Andrade ${ }^{1}$ \\ Luan Moreira Machado ${ }^{2}$ \\ Leandro Alberto da Silva ${ }^{3}$ \\ Giselle Faria dos Santos ${ }^{4}$
}

\begin{abstract}
RESUMO
Esse artigo aborda o tema gestão democrática na escola pública no contexto de um novo modelo de gestão, denominado "Nova Gestão Pública" (NGP) ou "Gerencialismo". Tem-se como objetivo discutir a implementação da gestão democrática da escola pública nesse contexto de mudanças, com repercussões diretas na organização, na estrutura escolar e na administração. Aborda-se o conceito implícito na expressão "gestão democrática" e mecanismos estabelecidos na LDB, no 9394, de 1996, diante dos fundamentos e processos da NGP em movimento. Discute-se as possibilidades de implementação da gestão democrática na educação pública no cenário atual, tendo como base de discussão a participação coletiva, a construção do diálogo, mas também os embates e divergências da nova forma de gerenciamento da escola. Metodologicamente, o artigo foi elaborado a partir da pesquisa bibliográfica e análise de documentos normativos da educação e apresenta contribuições importantes para os gestores e profissionais da educação que se encontram no exercício da docência ou da gestão escolar. Os aspectos da gestão democrática são analisados confrontando-se com aspectos de uma nova gestão pública em andamento em contraposição ao antigo e obsoleto modelo burocrático. Destaca também os princípios e convicções do gerencialismo, colocando em pauta a ocupação do gestor nas instituições de ensino e suas responsabilidades e dificuldades diante das novas exigências demandadas pelas mudanças na organização e estrutura escolar implementação de novas práticas de gestão.
\end{abstract}

Palavras-chave: Nova Gestão Pública. Democracia. Gerencialismo. Educação. Participação.

\footnotetext{
${ }^{1}$ Doutorado em Educação pela PUC SP e mestre em Ciências da Linguagem pela Universidade do Vale do Sapucaí (Univás). Graduado em Ciências Contábeis e em Administração de Empresas, pela Faculdade de Economia e Finanças do Rio de Janeiro (Suesc) Atualmente é, professor Permanente do Mestrado em Educação, coordenador do Curso de Ciências Contábeis e docente da Univás, Brasil. E-mail: n.lambert@uol.com.br

${ }^{2}$ Mestrando em Educação pela Universidade do Vale do Sapucaí (UNIVÁS) possui graduação em Ciências Contábeis pela Universidade do Vale do Sapucaí (UNIVÁS). Atualmente é um dos Contadores da Fundação de Ensino Superior do Vale do Sapucaí, Brasil. E-mail: Iuanmachado201492@gmail.com

${ }^{3}$ Graduado em Engenharia Industrial Química pela USP - Escola de Engenharia de Lorena. Atualmente sou professor titular da escola SESI / SENAI na cidade de Pouso Alegre, em Minas Gerais, Brasil. E-mail: leandro.alberto@fiemg.com.br

${ }^{4}$ Mestranda em Educação e Bacharel em Enfermagem pela Universidade do Vale do Sapucaí (Univás), Brasil. E-mail: gisellefariados@gmail.com
} 


\begin{abstract}
This article addresses the theme of democratic management in public schools in the context of a new management model, called "New Public Management" (NPM) or "Managerialism". The objective is to discuss the implementation of the democratic management of the public school in this context of changes, with direct repercussions on the organization, the school structure and the administration. The concept implicit in the expression "democratic management" and mechanisms established in the LDB, $\mathrm{n}^{\circ}$ 9394, of 1996, are addressed, given the fundamentals and processes of the NGP in motion. The possibilities of implementing democratic management in public education in the current scenario are discussed, based on the discussion of collective participation, the construction of dialogue, but also the clashes and divergences of the new form of school management. Methodologically, the article was elaborated from the bibliographic research and analysis of normative documents of education and presents important contributions for the managers and professionals of education who are in the exercise of teaching or school management. Aspects of democratic management are analyzed against aspects of a new public management in progress, in opposition to the old and obsolete bureaucratic model. It also highlights the principles and convictions of managerialism, placing on the agenda the occupation of the manager in educational institutions and his responsibilities and difficulties in the face of the new demands demanded by changes in the organization and school structure, implementation of new management practices.
\end{abstract}

Keywords: New Public Management. Democratic management. Managerialism. Public education.

\title{
1 INTRODUÇÃO
}

Este artigo aborda o tema gestão democrática da escola pública no contexto de implementação da nova gestão pública. Apesar das discussões sobre gestão democrática, no Brasil, remontarem à década de 1980, período em que as discussões foram mais acirradas em torno da redemocratização do país e dos movimentos pela democratização da educação, considera-se que o tema é recorrente, em face a um novo contexto que se instalou a partir da década de 1990. Após mais de 30 anos, o tema ainda mobiliza grandes embates e tensões no âmbito político e educacional a fim de dar sequência a um princípio posto constitucionalmente (BRASIL, 1988) e confirmado na Lei de Diretrizes e Bases da Educação Nacional (LDB), No 9394 de 1996. Mudam-se o cenário, as leis, as formas de gestão, todavia tornar a gestão democrática uma realidade nas instituições de ensino públicas continua sendo ainda um dos grandes desafios.

Nesse contexto, o artigo busca analisar os princípios da gestão democrática, enquanto política e princípio jurídico, conforme Constituição Federal, e os procedimentos estabelecidos na Lei de Diretrizes da Educação Nacional (LDB), n. ${ }^{\text {o }}$ 9394 de 1996 e os confrontam com os desafios da sua implementação nas escolas da educação básica no contexto da reforma, que vem se dando no cenário educacional a partir do final da década de 1990: um modelo de gestão que tem sido denominado por pesquisadores, como Oliveira (2015), de "Nova Gestão Pública" (NGP) ou também tratada como "gerencialismo" (BARROSO, 1995).

Independentemente da denominação, considera-se que o novo modelo de administração pública se trata de um movimento de reformas que vêm ocorrendo em nível internacional desde a década de 1970 no Reino Unido e, desde 1980, nos Estados Unidos, chegando ao Brasil na década de 1990 com o Plano Diretor da Reforma do Aparelho de Estado (PDRAE), liderado pelo então ministro da Reforma, Luiz Carlos Bresser Pereira (1995), então Ministro da Reforma (MARE), no Governo Fernando Henrique Cardoso (FHC). O plano se apresenta com foco na desburocratização da administração pública e na institucionalização de uma gestão voltada para a eficiência e resultados (OLIVEIRA, 2015), caracterizada como administração "gerencial". 
Considerando as características da chamada "gestão democrática" que já se tornaram comuns no cenário educacional, a questão que instiga este artigo se refere às possibilidades de implementação da gestão democrática na educação pública diante deste cenário de mudanças na administração pública do Estado brasileiro, denominado "Nova Gestão Pública" (NGP) ou "Gerencialismo".

$\mathrm{O}$ artigo foi elaborado no decorrer do desenvolvimento da disciplina "Políticas Educativas, Gestão e Avaliação da Educação", no curso de Mestrado em Educação de uma universidade localizada no Sul de Minas Gerais. Considerando a abrangência dos temas envolvidos, a vivência acadêmica e profissional do grupo de alunos da referida disciplina e a experiência do professor em cargos de gestão da educação superior, inclusive no cargo coordenação da Comissão Própria de Avaliação (CPA), a elaboração deste artigo fez parte da metodologia de ensino adotada na disciplina. Pelo fato de as aulas terem sido abruptamente interrompidas devido à epidemia da Covid-19, as aulas passaram a ser desenvolvidas de forma síncrona, on-line, o que exigiu um redesenho da metodologia, tanto no desenvolvimento de conteúdos como de avaliação.

Dessa forma, foi priorizada a produção científica colaborativa, na linha de ensinar pela pesquisa como metodologia, o que significou promover o diálogo entre docentes da disciplina e mestrandos, os conteúdos planejados para a disciplina e a distribuição dos alunos em quatro grupos com a proposta de diversas leituras e a elaboração do artigo sob a supervisão e participação de docentes do mestrado. Passou-se a utilizar a metodologia análoga ao modelo de "sala de aula invertida" em que as propostas de leitura e atividades, dentre elas a realização do artigo, foram lançadas antecipadamente aos alunos e postadas no na plataforma, ora utilizada. A leitura em casa dos textos selecionados para disciplina e a posterior discussão nas aulas remotas, com a utilização da Plataforma Microsoft Teams, possibilitou a redação coletiva deste artigo, com o recurso do Google Sala de Aula.

Optou-se pelo tema central da disciplina, com o foco se concentrando em dois eixos, a saber: gestão democrática da escola pública e a nova gestão pública na política educacional brasileira, também denominada "Gerencialismo". O recorte temporal adotado foi a década de 1990, com ênfase na publicação da Lei de Diretrizes e Bases da Educação Nacional (LDB), $\mathrm{n}^{\circ} 9$ 394, publicada em 1996. Neste contexto, foram selecionados autores que têm se debruçado a discutir o tema tomado como objeto de estudo no contexto pós publicação da referida LDB, também caracterizado pelas reformas oriundas de políticas neoliberais, nacionais e internacionais, com forte repercussão no sistema educacional brasileiro, em todos os níveis, principalmente nos processos de gestão da educação pública. A metodologia adotada se apoia na pesquisa bibliográfica e documental, em atos normativos e dados do Anuário da Educação Básica (2019), somando-se também as discussões realizadas em sala de aula.

O texto encontra-se estruturado em três partes, além da introdução e das considerações finais. Primeiramente, são apresentados fundamentos e características do movimento de reforma que tem dado origem ao novo modelo de administração pública no Brasil (NGP), baseado no modelo empresarial; em seguida, são abordados conceitos e premissas de gestão democrática da educação em atos legais e, por fim, discute-se o papel do gestor para que ocorra a gestão democrática com base em atos normativos, como Constituição da Federal de 1988 e LDB, n. ${ }^{\circ}$ 9394, de 1996, bem como no Plano Nacional de Educação (PNE 2014-2024) e resultados de pesquisas já publicadas, com destaque a de Oliveira, Duarte e Clementino (2017). O artigo apresenta contribuições importantes para os gestores e profissionais da educação que se encontram no exercício da docência e/ou da gestão escolar. 


\section{NOVA GESTÃO PÚBLICA (NGP) E PLANO DA REFORMA}

Parte-se do princípio de que a chamada NGP é ainda um tema pouco conhecido com essa nomenclatura pelos profissionais da educação e pelos próprios gestores no cenário educacional. A origem da administração da educação no Brasil pode ser contextualizada a partir do contexto da administração pública, no âmbito da política econômica, científica e cultural do país (SANDER, 2007). No caso do termo "gestão", este é relativamente ainda pouco compreendido no cenário educacional e tem a sua origem do cenário empresarial (CÁRIA, 2015). Ao se deslocar para a área da educação tem recebido críticas por pesquisadores pelo seu caráter ligado às práticas neoliberais, mas no ambiente escolar, entre os docentes e gestores, pouco ou nada se discutem sobre os aspectos envolvidos no significado do termo "gestão", conforme analisado por Cária (2015). Conforme a autora, desde as últimas décadas do século anterior, o termo passou a ser utilizado para substituir o termo "administração" "sendo o intercâmbio destes termos feito com frequência de maneira indiscriminada, tanto no cenário empresarial como no cenário educacional" (p. 19).

Diante do exposto, a delimitação do conceito de gestão se faz importante, justamente, tendo em vista o seu uso indiscriminado e a parca visibilidade do seu sentido de origem. O termo "gestão" deriva do latim gerere, que significa administrar, ato de gerir, conduzir, gerência. Comparado com o sentido de "administração", que também deriva do latim administrare e significa gerir, ação de administrar, gestão, gerência, função de administrar. Dessa forma, no dizer comum, a ideia de gestão sempre se apresenta vinculada ao sentido de gerencialismo que, por sua vez, se refere a processos de gerenciamento. É possível observar que, etimologicamente, os termos possuem o mesmo sentido, sendo a diferença apenas na nomenclatura. Entretanto, como analisado por Cária (2015), ainda não há entre os autores/pesquisadores um consenso quando se analisam os dois termos. No entendimento de Oliveira (2015), pode-se considerar que existe um consenso de que "o termo gestão é mais amplo e aberto que administração", enquanto para Barroso (1995), administrar e gerir compreendem coisas diferentes, mas todas ligadas ao modo de administrar, não significando, entretanto, a mesma coisa.

Neste artigo, adotando o conceito de gestão como gerenciamento (BARROSO, 1995), procura-se problematizar o conceito implícito na expressão "gestão democrática" e seus mecanismos democráticos estabelecidos na Lei de Diretrizes e Bases da Educação Nacional (LDB), n. ${ }^{\circ}$ 9394, de 1996, confrontados com os fundamentos e os processos da NGP em implementação no Brasil nas últimas décadas. Com base em Cóssio (2018) e Oliveira (2015), considera-se que, em outros países, principalmente no Reino Unido, considerado seu berço, a NGP começou a ser implantada por volta dos anos 1970. Posteriormente foi encampada nos Estados Unidos nos anos 1980 e logo se espalhou para outras localidades do mundo, inclusive no Brasil a partir da década de 1990, com fortes repercussões no cenário educacional, em geral, e na gestão educacional, em particular. Portanto, observa-se que não se trata mais de uma tendência de mudanças na gestão da educação, mas de uma realidade que tem se instalado progressivamente em todos os níveis de ensino.

Especificamente no caso brasileiro, a administração pública gerencial surgiu na segunda metade do século XX e foi uma resposta à crise de Estado: de um lado as crescentes funções que o Estado exercia, como as econômicas e sociais, e, de outro, os avanços das tecnologias e a globalização da economia mundial, uma vez que ambos, demonstraram a ineficiência da máquina pública (BRESSER-PEREIRA, 1995). Dentre 
outros, esses fatos levaram à necessidade de um reequilíbrio fiscal e financeiro nas contas públicas, além de uma reestruturação drástica da antiga forma de gestão, caracterizado como modelo burocrático, preservando os seus pontos positivos.

Para solucionar os problemas que o modelo burocrático apresentava como o alto custo de operação e a má qualidade dos serviços prestados, dentre outros, o plano de reestruturação do Estado se apresentou com a proposta de realinhamento das relações entre Estado, cidadania, economia e nova forma de organização do modelo de administração, com repercussões diretas nas políticas e formas de gestão da educação e da escola, como explicado por Cária (2015). No contexto deste remodelamento foi proposta uma nova gestão pública, voltada para o gerenciamento, a eficácia e a racionalização administrativa, também denominada gerencial.

\begin{abstract}
Algumas características básicas definem a administração pública gerencial. É orientada para o cidadão e para a obtenção de resultados; pressupõe que os políticos e os funcionários públicos são merecedores de um grau limitado de confiança; como estratégia, serve-se da descentralização e do incentivo à criatividade e à inovação; o instrumento mediante o qual se faz o controle sobre os gestores públicos é o contrato de gestão (BRESSER-PEREIRA; SPINK, 1998 p. 28).
\end{abstract}

Nessa mesma linha, autores como Hood (1991), no início da década de 1990, já definia que a "Nova Gestão Pública" se pauta em sete princípios: capacitação na gestão públicas; avaliação de desempenho; uso das técnicas de gestão usados no setor privado; controle de resultados; fragmentação das grandes unidades do setor público; inserção da concorrência no setor público e eficiência no uso de recursos públicos. Dessa forma, esse novo modelo de gestão pública (NGP), articulado em meio às discussões em torno de uma proposta de reforma do aparelho de Estado para torná-lo mais eficiente e menos burocrático (BRESSER-PEREIRA, 1995), o que recebeu também denominações diferentes, mas significando a mesma coisa. Para Shepherd e Valencia (1996), a "Nova Gestão Pública" pode ser denominada de gerencialismo, novo gerencialismo, nova gerência pública ou gerência baseada no desempenho. Segundo Bresser-Pereira e Spink (1998), eles optaram por adotar o uso do termo "Administração Pública Gerencial”.

Nessas circunstâncias, a NGP pode ser considerada como uma reforma na Administração Pública Gerencial, que tem como objetivo reduzir as ações e o tamanho do Estado. Esse modelo se embasa nas técnicas gerenciais da iniciativa privada e, através dessas medidas, obter a redução dos custos e aumentar a eficiência da máquina pública sem comprometer o seu funcionamento.

[...] Administração Pública que chamaria de "gerencial", baseada em conceitos atuais de administração e eficiência, voltada para o controle dos resultados e descentralizada para poder chegar ao cidadão, que, numa sociedade democrática, é quem dá legitimidade às instituições e que, portanto, se torna "cliente privilegiado" dos serviços prestados pelo Estado (BRASIL, 1995 p.7).

Segundo Bresser-Pereira (1995), a Nova Gestão Pública é uma resposta a toda globalização, que hora havia tomado conta de todos os países juntamente com o poder da democracia, que dava direitos plenos ao cidadão e à sociedade como um todo, para tornar o Estado "Moderno" e mais eficiente. Conforme o autor, a crise econômica no Brasil não era diferente dos países desenvolvidos, com o aumento descontrolado dos gastos públicos nas décadas de 1980 e início da próxima, fazendo com que o país enfrentasse a hiperinflação, o que acabava minimizado o poder de compra da população 
e atingia diretamente a economia. Algumas estratégias eram adotadas como o congelamento de preços dos produtos nos supermercados, porém, sem êxito nas medidas adotadas pelo Governo.

Para estabilizar a hiperinflação, Fernando Henrique Cardoso (FHC), então Ministro da Fazenda do presidente Itamar Franco (1992-1995), desenvolveu o Plano Real em 1994, que foi responsável para solucionar os problemas de hiperinflação que corroía a economia brasileira; essa medida garantiu o retorno do poder de compra da população além de estabilizar o consumo. O Plano Real foi considerado primordial para que FHC fosse eleito presidente da república nas eleições de 1994 e, posteriormente, uma reforma na administração pública. Em 1995, FHC já eleito como presidente da república, colocou em discussão a necessidade de uma reforma na Gestão Pública, conforme apresentado na carta de apresentação do documento intitulado "Plano Diretor da Reforma do Aparelho de Estado" (BRASIL, 1995). Na apresentação do documento da reforma, FHC assim se expressa:

É preciso, agora, dar um salto adiante, no sentido de uma administração pública que chamaria de "gerencial", baseada em conceitos atuais de administração e eficiência, voltada para o controle dos resultados e descentralizada para poder chegar ao cidadão, que, numa sociedade democrática, é quem dá legitimidade às instituições e que, portanto, se torna "cliente privilegiado" dos serviços prestados pelo Estado (BRASIL/FHC, 1995, p. 7).

No entendimento de FHC (1995), dessa maneira, o Estado seria capaz de reduzir o seu papel estratégico de prestador direto de serviços, mas se mantendo no papel de promotor ou regulador, especialmente, aqueles voltados para os serviços sociais como a educação e a saúde, que são fundamentais para o desenvolvimento humano e para a democracia, na medida em que os cidadãos são promovidos, além de garantir a distribuição de renda mais igualitária entre a população. O Plano Diretor da Reforma do Aparelho do Estado (PDRAE), publicado em 1995, no Governo de Fernando Henrique Cardoso (1995-2003), liderado por Luiz Carlos Bresser-Pereira, então ministro da Administração Federal e Reforma do Estado, propôs que a reforma administrativa fosse incluída entre as reformas constitucionais já definidas como prioritárias pelo novo Governo, quais sejam: reforma fiscal, reforma da previdência social e a eliminação dos monopólios estatais.

A proposta é implementar uma "administração pública moderna e eficiente, compatível com o capitalismo competitivo em que vivemos" (BRESSER-PEREIRA; SPINK, 1998 p. 21). Para isso, conforme os autores, seria necessário flexibilizar o estatuto da estabilidade dos servidores públicos de forma a aproximar os mercados de trabalho público e privado. É possível observar que, por meio da reforma, está evidente a proposta de aproximação do modelo de gestão empresarial na administração pública. Segundo Mota Júnior e Maués (2014), as reformas educacionais concebidas e executadas pelo governo brasileiro nos anos 1990 foram, em particular, profundamente influenciadas pelos diagnósticos e orientações do Banco Mundial, sobretudo durante os oito anos de governo de FHC (1995-2002). De acordo com os autores, "no cerne das propostas do Banco Mundial para as reformas educacionais nos países periféricos, entre eles o Brasil, estavam a ênfase na educação básica, a descentralização da gestão e a centralização da avaliação dos sistemas escolares. Entretanto, essa reforma do Aparelho de Estado se apresenta no documento PDRAE como forma de contribuir com uma nova "governança", que agora deverá ser "democrática", de acordo com o documento (BRASIL, 1995), considerando os direitos do "cliente" que passa a substituir a 
referência ao cidadão: "É pelo diálogo democrático entre o Estado e a sociedade que se definem as prioridades a que o Governo deve ater-se para a construção de um país mais próspero e justo" (BRASIL, 1995, p. 9).

Conforme consta no documento PDRAE (1995), os principais objetivos na NGP no Brasil são:

\begin{abstract}
Aumentar a governança do Estado, ou seja, sua capacidade administrativa de governar com efetividade e eficiência, voltando a ação dos serviços do Estado para o atendimento dos cidadãos;

Limitar a ação do Estado àquelas funções que lhe são próprias, reservando, em princípio, os serviços não-exclusivos para a propriedade pública nãoestatal, e a produção de bens e serviços para o mercado para a iniciativa privada;

Transferir da União para os estados e municípios as ações de caráter local: só em casos de emergência cabe a ação direta da União;

Transferir parcialmente da União para os estados as ações de caráter regional, de forma a permitir uma maior parceria entre os estados e a União (BRASIL, 1995, p.45).
\end{abstract}

Os resultados das políticas públicas implantadas pela NGP são de longo prazo, talvez, para a maioria das pessoas na década, a partir de 1995, essa reforma passou despercebida devido à complexidade e o tamanho do Brasil e, atualmente, nem se ouve mais falar deste assunto. No entanto, essa reforma está em andamento e tem sido essencial para diminuir os excessos burocráticos e, ao mesmo tempo, permitindo a adoção de práticas respaldadas em características da NGP, mas sempre fundamentadas no diálogo democrático entre Estado e sociedade para fundamentar as prioridades do Governo no que se refere a uma gestão pública. Democracia e gestão democrática podem ser consideradas premissa básica da chamada NGP, inclusive na área educacional.

\footnotetext{
Estado e sociedade formam, numa democracia, um todo indivisível. O Estado, cuja competência e limites de atuação estão definidos precipuamente na Constituição, deriva seu poder de legislar e de tributar a população, da legitimidade que lhe outorga a cidadania, via processo eleitoral. A sociedade, por seu turno, manifesta seus anseios e demandas por canais formais ou informais de contato com as autoridades constituídas (BRASIL, 1995, p.9).
}

Nesse contexto, pelo menos teoricamente, pressupõe que a população tem o papel fundamental na participação da gestão uma vez que são os beneficiados dessa reforma. Embora contestada por muitos, encontram-se envolvidos os interesses coletivos e não pessoais de quem administra os recursos públicos, o que deve ser de forma democrática, a discussão em torno das reformas necessárias tem sido acalorada, polêmica e se arrasta entre as diversas instâncias, ditas democráticas, do Estado e o que percebe nas análises midiáticas é que as reformas em andamento não atendem às necessidades e anseios de grande parte do povo brasileiro. Pesquisa realizada por Oliveira, Duarte e Clementino (2017) analisam mudanças ocorridas na realidade escolar brasileira com as reformas educacionais iniciadas nos anos 1990 diante do processo de regulação e suas repercussões na prática da gestão escolar e na organização do trabalho pedagógico.

Os dados obtidos nas entrevistas com diretores(as) das escolas se relacionaram às seguintes categorias: condições de trabalho; relação de poder (presença de conflitos); percepções sobre a gestão escolar; motivações para o exercício da gestão; concepção de educação (ensino); concepção de justiça social e de justiça escolar; compreensão e 
definição do termo qualidade em educação; preocupação com os resultados escolares; preocupação com o futuro dos alunos; estratégias de ação para atingir os objetivos (metas).

A partir desses aspectos/categorias, Oliveira, Duarte e Clementino (2015) analisam os dilemas dos profissionais que ocupam cargos de gestão na escola pública, dentre eles, o fato de atuarem no limite dos recursos disponíveis e das condições objetivas para a realização do trabalho educativo nas instituições escolares. Muitas se apresentam em condições estruturais precárias, localizadas em regiões de vulnerabilidade social, contam com equipe reduzida de apoio administrativo e, muitas vezes, o peso das responsabilidades e decisões recaem sobre o diretor ou diretora da escola. Eles confirmam que, há um "redesenho da gestão escolar que vem se definindo com a introdução da NGP, porém carece de maiores estudos. Isso devido à diversidade de questões e situações que estão envolvidas no processo de gestão da escola, inclusive geradas por parte dos próprios sujeitos envolvidos, além das especificidades locais, regionais e nacionais.

\section{A GESTÃO DEMOCRÁTICA NO ASPECTO LEGAL}

A educação brasileira é sustentada por três pilares legais, que são a Constituição Federal (1988), a Lei de Diretrizes e Bases da Educação Nacional (LDB) (1996) e o Plano Nacional da Educação (PNE 2014-2024), são elas que promovem a gestão democrática no âmbito educacional. A tendência democrática na educação brasileira é patente na legislação do ensino nas práticas de gestão educacional e na produção acadêmica das assembleias de educadores (AGUIAR, 2016). A prática democrática requer essencialmente o desenvolvimento e o aperfeiçoamento de todos que atuam na instituição, no sentido de que compreendam a complexidade do trabalho pedagógico e a importância da contribuição individual e coletiva para sua realização. Como descrito por Bordignon e Gracindo (2001), a gestão democrática pode ser compreendida como um objetivo a ser sempre buscado, aperfeiçoado, se configurar como uma prática que deve se tornar habitual nos espaços educativos. No entanto, a efetivação da gestão democrática da educação apresenta um desafio de grandes proporções, pois implica uma filosofia política e uma estratégia de ação pedagógica (SANDER, 2007).

As discussões que envolvem a questão da gestão democrática da escola pública remontam ao início da década de 1980. Nessa década, no Brasil, o tema gestão democrática integrava a pauta dos educadores que reivindicavam, entre outros, mecanismos de participação nos processos decisórios da escola, tais como: eleição de dirigentes escolares, instituição de conselhos escolares, elaboração de regimento e de projeto pedagógico de forma coletiva, exclusividade do financiamento da escola pública pelo poder público. "Buscava-se instalar mecanismos de gestão baseados na organização democrática dos diferentes setores que compunham a 'comunidade escolar"”, como explica Adrião (2006, p. 57).

A Constituição Federal foi publicada no auge dessa discussão de 1988, contemplando o princípio da gestão democrática nas instituições de ensino pública. No entendimento de Saviani (2013, p. 216), “[...] a gestão democrática expressava os anseios dos professores de participação nas decisões, em contraposição à sua exclusão levada a efeito pelo regime autoritário", o que mostra apenas um foco da gestão democrática. Entre as conquistas, vale pontuar que a Constituição Federal de 1988 garante o acesso à educação para todos, conforme estabelece o art. 2005:

A educação, direito de todos e dever do Estado e da família, será promovida e incentivada com a colaboração da sociedade, visando ao pleno 


\section{pública}

desenvolvimento da pessoa, seu preparo para o exercício da cidadania e sua qualificação para o trabalho (BRASIL, 1988).

A própria o documento da Carta Magna cita a gestão democrática e define os conceitos que o ensino deverá seguir como orientação no do art. 206, onde se lê que o ensino será ministrado com base nos seguintes princípios:
I - Igualdade de condições para o acesso e permanência na escola;
II - Liberdade de aprender, ensinar, pesquisar e divulgar o pensamento, a arte e o saber;
III - pluralismo de ideias e de concepções pedagógicas, e coexistência de instituições públicas e privadas de ensino;
IV - Gratuidade do ensino público em estabelecimentos oficiais;
V - Valorização dos profissionais da educação escolar, garantidos, na forma da lei, planos de carreira, com ingresso exclusivamente por concurso público de provas e títulos, aos das redes públicas;
VI - Gestão democrática do ensino público, na forma da lei;
VII - Garantia de padrão de qualidade;
VIII -Piso salarial profissional nacional para os profissionais da educação escolar pública, nos termos de lei federal (BRASIL, 1988).

Com a publicação da LDB, n $^{\circ}$ 9394, em dezembro de 1996, pode-se identificar três princípios que conduzem a uma gestão democrática: a descentralização, participação e transparência. Como apontado por Cury (1999), considerando que a educação é um serviço público pode-se deduzir que a sua gestão deva fundamentar-se na participação de todos, mas argumenta que tal afirmação não resiste à história. Isso porque o "público" diz respeito ao fato de ser um serviço ofertado pelo Estado e destina-se a toda população em geral, não significando que essa população seja consultada, como revela a história na análise de Cury (1999).

As instituições públicas e privadas que ofertam a Educação Básica, devem sempre ser administradas com base na LDB, que evidencia os termos assegurados sobre os princípios da gestão democrática nos artigos $3^{\circ}, 14^{\circ} 27^{\circ}$ e $56^{\circ}$.

Art. $3^{\circ}$. O ensino será ministrado com base nos seguintes princípios:

VIII - gestão democrática do ensino público, na forma desta Lei e da legislação dos sistemas de ensino; (BRASIL, 1996).

Art. $14^{\circ}$. Os sistemas de ensino definirão as normas da gestão democrática do ensino público na educação básica, de acordo com as suas peculiaridades e conforme os seguintes princípios:

I - Participação dos profissionais da educação na elaboração do projeto pedagógico da escola;

II - Participação das comunidades escolar e local em conselhos escolares ou equivalentes. (BRASIL, 1996).

Art. 27. Os conteúdos curriculares da educação básica observarão, ainda, as seguintes diretrizes:

I - A difusão de valores fundamentais ao interesse social, aos direitos e deveres dos cidadãos, de respeito ao bem comum e à ordem democrática; (BRASIL, 1996).

Art. 56. As instituições públicas de educação superior obedecerão ao princípio da gestão democrática, assegurada a existência de órgãos colegiados deliberativos, de que participarão os segmentos da comunidade institucional, local e regional. (BRASIL, 1996).

No início do século XXI, a educação brasileira com o Plano nacional de Educação (PNE 2001-2010) com validade de uma década. O segundo PNE, objeto de estudo neste artigo, ocorreu com a publicação da Lei Federal $n^{\circ} 13.005$, de 25 de junho 
de 2014, conhecido como Plano Nacional de Educação (PNE 2014-2024). Conforme previsto no art. 214, da Constituição Federal, a gestão democrática se apresenta citada dentre as metas e diretrizes do PNE: "Art. $2^{\circ}$, item VI - promoção do princípio da gestão democrática da educação pública" (BRASIL, 2014). Neste sentido o PNE reforça o art. 206 da Constituição Federal sobre a Gestão democrática e os artigos $3^{\circ}, 14^{\circ}, 27^{\circ}$ e $56^{\circ}$ da LDB. O PNE destaca a necessidade para que os entes federados aprovem leis ligadas ao sistema educacional.

Art. $9^{\circ}$. Os Estados, o Distrito Federal e os Municípios deverão aprovar leis específicas para os seus sistemas de ensino, disciplinando a gestão democrática da educação pública nos respectivos âmbitos de atuação, no prazo de 2 (dois) anos contado da publicação desta Lei, adequando, quando for o caso, a legislação local já adotada com essa finalidade (BRASIL, 2014).

Observa-se, dentre essas normas e atos legais, que o incentivo e a promoção de mudanças na gestão da educação pública por parte do Ministério da Educação (MEC), com indução de princípios e convicções do gerencialismo. Nessa direção, pode-se dentre eles o papel da descentralização e da autonomia dentro das escolas, que traria uma responsabilização de toda a equipe da administração e dos docentes para o efetivo sucesso da instituição, como descrito, a seguir, por Lima (2003, p.31):

\begin{abstract}
A autonomia (mitigada) é um instrumento fundamental de construção de um espírito e de uma cultura de organização-empresa; a descentralização é congruente com a 'ordem espontânea' do mercado, respeitadora da liberdade individual e garantia de eficiência econômica; a participação é essencialmente uma técnica de gestão, um fator de coesão e de consenso. Assim, nesta perspectiva, conceitos como "autonomia", "comunidade educativa", " projeto educativo", continuarão a ser convocados, e até com maior frequência, mas como instrumentos essenciais de uma política de modernização e racionalização, como metáforas capazes de dissimularem os conflitos, de acentuarem a igualdade, o consenso e a harmonia, como resultados ou artefatos, e não como processos e construções coletivas.
\end{abstract}

Pelo exposto, descentralização e autonomia são características que fazem parte de um conjunto de elementos que definem uma gestão democrática, diante de uma política modernização e racionalização da educação. Trata-se de princípios que permeiam a nova gestão pública ao propor que os docentes e atores educacionais se transformem executores de metas e se responsabilizem pelos resultados dos seus alunos, o que exige competência e autonomia, sem desconsiderar aspectos legais que regulamentam a política da educação brasileira.

A responsabilização pode ser compreendida um fator de controle no entremeio do discurso da gestão democrática e da descentralização, pois impõe novas formas de gestão e não mera aplicação de procedimentos e técnicas, administrativas e pedagógicas, tampouco a aplicação automática de experiências e métodos. Ao contrário, trata-se de um compromisso com o ato pedagógico, crítico e responsável, com os resultados da aprendizagem.

\title{
4 O PAPEL DO GESTOR NA ESCOLA
}

A gestão escolar é o ato de administrar as situações culturais da escola, alinhando-se com as diretrizes de políticas públicas para a efetivação de seu projeto político pedagógico, mantendo-se ligados com os princípios da democracia, e com os procedimentos que possibilitem as condições necessárias para um ambiente educacional 
independente, participativo e equilibrado (LÜCK, 2009). Nesse sentido, uma das incumbências do gestor da escola é a organização, a junção e conexão de todas as condições materiais e humanas, que são primordiais para estabelecer o progresso, o desenvolvimento e a responsabilização de propiciar o melhor e mais efetivo aprendizado aos alunos, que são beneficiários das políticas educacionais.

Segundo Zenardini (2006), a gestão democrática tem como base os princípios e modelos que se opõem diretamente ao formato da gestão burocrática, que possui uma inflexibilidade em suas normas e regras, bem como centraliza suas funções no Estado. Não se trata de olhar um modelo contra o outro, mas como um processo de transição e, para isso, faz-se necessário criar condições para a efetivação de uma nova forma de gerir os processos educacionais.

Pode-se definir, portanto, a gestão democrática, como sendo o processo em que se criam condições e se estabelecem as orientações necessárias para que os membros de uma coletividade, não apenas tomem parte, de forma regular e contínua, de suas decisões mais importantes, mas assumam os compromissos necessários para a sua efetivação (LÜCK, 2009 p.71).

No que se refere a "criar condições", Lück (2009, p. 71), considerando as novas exigências educacionais originadas do impacto das atuais transformações econômicas, políticas, sociais e culturais, defende que mudanças mais significativas se fazem necessárias na gestão da escola, que possibilite uma melhor adequação às novas demandas e, assim, proporcionar uma educação de qualidade. Não há dúvidas que isso requer modificações na gestão, cabendo ao gestor ter como um de seus princípios, os fatores internacionalmente ditos como responsáveis pelo sucesso educativo das escolas, tais como: liderança, visão e metas compartilhadas, ambiente propício para a aprendizagem, propósitos definidos, projeto pedagógico coletivo, expectativas elevadas de qualidade, reforço positivo de atitudes, monitoramento das ações da escola como estratégia de gestão, parceria família-escola, gestão orientada para aprendizagem de todos os a gentes da escola.

Nesse sentido, deve se destacar o papel fundamental do gestor educacional, que tem a função de promover a gestão democrática nas instituições de ensino com todas as suas peculiaridades, além de suas responsabilidades com o processo pedagógico, cabendo a ele analisar, solucionar e orientar as dúvidas recorrentes das atividades pedagógicas, inclusive implementar e supervisionar a elaboração Projeto Político Pedagógico (PPP), que é um documento de caráter obrigatório e democrático utilizado nas instituições.

O PPP está relacionado diretamente com a LDB 9394/1996 que estabelece no Art. $14^{\circ}$, Item I "participação dos profissionais da educação na elaboração do projeto pedagógico da escola". Isso quer dizer que não é somente o gestor o responsável pelas tomadas de decisões, mas, elas devem se dar de forma colegiada ou mais coletiva possível, bem como democrática, envolvendo todos os profissionais ligados à educação ou os colegiados.

Promover essa participação e orientar os envolvidos no desenvolvimento de competências de avaliação constitui, portanto, um trabalho importantíssimo a ser exercido pelo diretor escolar: a realização de análises objetivas da realidade, o cuidado com a precisão e correção das informações, o raciocínio lógico-reflexivo, a visão interativa e abrangente são alguns dos aspectos importantes a serem desenvolvidos pelas pessoas que participam do planejamento educacional, seja em que dimensão for. (LÜCK, 2009 p.40). 
Contudo, ainda existem gestores que centralizam suas funções de maneira rígida e individual, o que acaba impossibilitando a outros profissionais da educação apresentarem suas sugestões e ideias, fazendo com eles permaneçam, de certa forma, alheios às decisões e, assim, demonstrem pouco ou nenhum envolvimento com a gestão da escola. Esse engessamento é prejudicial não só no contexto pedagógico, mas em todas as organizações. Na educação, impede o desenvolvimento dos professores, já que eles não são incentivados a contribuir com seus conceitos, observações e ideias.

\begin{abstract}
Muitos dirigentes escolares foram alvos de críticas por práticas excessivamente burocráticas, conservadoras, autoritárias, centralizadoras. Embora aqui e ali continuem existindo profissionais com esse perfil, hoje estão disseminadas práticas de gestão participativa, liderança participativa, atitudes flexíveis e compromisso com as necessárias mudanças na educação (LIBÂNEO, 2004, p.217).
\end{abstract}

Apesar de ainda existirem gestores imbuídos desse conceito e ainda adotarem essas práticas que ainda estão filiadas ao modelo tradicional, considerado centralizador, observa-se uma evolução quanto à existência de conselhos ou colegiados no âmbito das escolas públicas, que um dos indicadores que permitem avaliar o desenvolvimento da gestão democrática. Conforme dados do Anuário da Educação Básica Brasileira (2019, p. 116), no que se refere às instâncias participativas, em 2014, não havia Conselhos Municipais de Educação "em 12,4\% dos municípios brasileiros", conforme os últimos dados disponíveis. "Em 2017, 7,8\% dos estabelecimentos públicos de ensino não apresentavam Conselho Escolar". Além disso, em 61,8\% dos conselhos, havia participação de todos os atores envolvidos no processo de ensino e aprendizagem (professores, funcionários, alunos e pais). Nos demais, conforme descrito no documento, a representação era menor, especialmente pela ausência do corpo discente.

Pode-se considerar consenso que, entre os profissionais da educação, incluindo os gestores, ainda existe certa resistência às mudanças que vêm acontecendo nos últimos anos. Apesar de ainda existir gestores imbuídos do conceito tradicional de administração escolar, há uma clara mudança nas instituições, na qual os gestores atendem os requisitos legais e de forma democrática, como analisado por Lück (2009, p. 23).

\footnotetext{
Não se recomenda, nem se justifica, a divisão de trabalho nas escolas, como muitas vezes ocorre, delimitando-se para o diretor a responsabilidade administrativa e para a equipe técnico-pedagógica a responsabilidade pedagógica. Estes profissionais são participantes da liderança pedagógica exercida pelo diretor, exercendo essa responsabilidade em regime de coliderança. Ao diretor compete zelar pela escola como um todo, tendo como foco de sua atuação em todas as ações e em todos os momentos a aprendizagem e formação dos alunos.
}

Algumas mudanças que estão sendo adotadas nas escolas para atender às prescrições legais da constituição "democrática" da gestão é a escolha do gestor educacional pela sociedade ou pelo corpo docente e não por indicação política. Essa medida, segundo Lück (2009), aproxima a escola da comunidade que participa e contribui nas decisões, isso acaba estreitando os vínculos da sociedade com a gestão democrática na escolar.

No contexto da democratização da escola, de modo a torná-la uma instituição aberta à comunidade e de qualidade para todos, além dos preceitos legais para a sua democratização, conforme proposto na legislação vigente, uma 
nova estratégia tem sido acrescentada, qual seja a escolha de diretores pela comunidade escolar, a partir dos pressupostos de que na medida em que a comunidade escolhe o seu diretor, compromete-se em apoiar a implementação de projeto político-pedagógico construído coletivamente, e passa a sentir-se parte atuante desse processo e da comunidade escolar (LÜCK, 2009, p.9).

Com base no exposto, isso não significa dizer que não haverá a presença de uma política do Estado; ela sempre estará presente de uma forma mais ampla a fim de determinar as metas e as diretrizes da instituição, legitimando-as, bem como garantir a sua execução, sem limitar a autonomia e as responsabilidades do gestor escolar a fim de não imobilizar as iniciativas e ações dos agentes escolares, inclusive do gestor.

Cabe por fim ressaltar que a gestão escolar tem papel relevante no caminhar do ensino já que fica responsável pela busca de inovações, apontamento de insuficiências, falhas erros e resoluções de problemas da instituição (LÜCK, 2009), sempre com foco na aprendizagem do aluno e nos resultados positivos das práticas educativas. Para tais condições e exigências, a gestão tem como ferramenta principal o uso de indicadores que podem apontar a imperfeição e o caminho correto a trilhar. $\mathrm{O}$ indicador é um instrumento que permite mensurar as modificações nas características de um sistema (DEPONTI, 2002), enquanto para o Instituto Nacional de Estudos Pedagógicos (INEP/MEC) (2008), o indicador é um dado agregado que traduz numericamente uma condição a ser analisada, conforme analisado por Lück (2009, p. 65).

O IDEB se constitui no indicador de maior evidência no momento, uma vez que combina resultados de testes padronizados e informações sobre o rendimento escolar, conforme anteriormente indicado. A escola pode acessar os seus resultados no site do INEP e compará-los com os do seu município, do seu estado e do país, além de poder ver a variação entre outros resultados.

No âmbito escolar podemos dizer que, realmente, ocorre na prática é a transferência de todos os planos, metas e afazeres para a responsabilidade da escola sob o nome da autonomia, o que na verdade não ocorre exatamente dessa forma, já que existem imposições e limitações sobre todos os planos e metas, como se refere Adrião (2006): "a autonomia das escolas públicas e privadas é sempre relativa, é limitada em função das normatizações legais e institucionais que as regem".

Como compreende Lück (2009), a gestão escolar se baseia em uma série de táticas e procedimentos norteados para promover modificações e transmutações dos processos educacionais de forma que tenha como principal objetivo a formação e o aprendizado eficiente dos alunos. Portanto, cabe considerar as tensões e conflitos se dão no dia a dia da escola, desde o planejamento às ações pedagógicas, sendo papel do gestor gerenciar as demandas apresentadas aos docentes, decorrentes das exigências de produtividade no que se refere aos resultados educacionais. Isso porque, no contexto da democratização da escola, a instituição aberta à comunidade deve também dar conta de oferecer serviços de qualidade para todos, em acordo com os preceitos legais que definem uma gestão democrática diante das novas estratégias de gestão da educação em movimento nas últimas décadas

\section{CONSIDERAÇÕES FINAIS}

Conforme demonstrado ao longo deste texto, a implementação da chamada gestão democrática não se trata de tão somente assegurar na Lei, pois não se trata de uma ação tão simples e linear, quando se considera os vários fatores aí envolvidos, 
principalmente diante desse novo modelo de gestão que está sendo implementado nas instituições de ensino pública a partir da década de 1990, sob a premissa da modernização. A gestão proposta na chamada "modernização" dos sistemas educativos, em suas formas de gerenciamento denominadas "Nova Gestão Pública", apresenta-se com diversas lacunas, principalmente quando se confrontam as características que definem a gestão democrática e as características do novo modelo de gestão, conforme apresentado ao longo deste texto, com diversos processos controle, regulação, avaliação e racionalização.

É importante considerar que educação brasileira tem passado por algumas mudanças, com alterações significativas na organização e estrutura escolar, com repercussões na gestão dos sistemas de ensino que, a partir da promulgação da Constituição Federal de 1988, passou a ser orientada pelo princípio da "gestão democrática". As discussões sobre gestão democrática vão ao encontro das questões sociais e suas relações com a educação pública que se tornaram explícitas a partir do final da década de 1970 e ganhando impulso na década de 1980. Seu pano de fundo é a participação dos agentes envolvidos nos processos decisórios da gestão escolar.

Nesse contexto, a nova gestão democrática nas escolas públicas tem sido implementada em meio a vários obstáculos e dificuldades devido à grande complexidade de gerenciamento da educação como política pública. O que se observa é que, na prática a chamada "gestão democrática" ainda adota o modelo antigo em que predomina, em diversos casos e espaços, a indicação política para diretores de escolas e não por meio do modelo popular e democrata, que usa as eleições diretas para a indicação e ocupação do cargo, a existência de conselhos que não funcionam, a administração da escola ainda é exercida por um "diretor" ou "diretora" e não por gestores, além da falta de conselhos.

A nova gestão pública ainda é um tema, praticamente, desconhecido no cenário escolar, mas teve seus primeiros passos na Constituição de 1988, despontando-se com efetividade com o presidente Fernando Henrique Cardoso por meio implementação do PDRAE. Uum plano que instituía linhas e diretrizes de um Governo voltado para tornar o Estado moderno e democrático, conforme o documento (BRASIL, 1995) que vem dando origem a novas políticas de educação e também em todas as demais áreas. Podese entender que o referido Plano é composto de mecanismos legais e institucionais, interligados não apenas à área da educação, mas, ao contrário, trata-se de mudanças na administração pública do Estado - de um modelo burocrático para o modelo "gerencial".

A participação, como princípio especial da gestão democrática, como princípio norteador na nova gestão pública da educação, impõe à gestão novos comportamentos e responsabilização; exige assumir o papel de coordenação de atitudes que levem à participação social e a liderança em todos os planos, seja no planejamento e na elaboração dos planos da escola, seja na elaboração de políticas educacionais, na tomada de decisões, na escolha dos destinos dos recursos da escola e prioridades de aquisição, na execução das resoluções colegiadas, nos processos de avaliação da escola e outros.

Por fim, é importante frisar que a democratização da educação está diretamente vinculada à forma de sua gestão da escola, que deve ser democrática numa perspectiva mais abrangente, não se tratando apenas de fazer constar em leis e/ou privilegiar a participação dos cidadãos na escola. O que se almeja é uma escola mais interativa, construída ou até mesmo reconstruída a partir da cooperação de todos, trazendo a interação e participação da sociedade em geral, com transparência e responsabilidade, uma administração objetiva e de excelência que possa garantir a todos os cidadãos uma educação de qualidade. 


\section{REFERÊNCIAS}

ADRIÃO, T. Educação e produtividade: a reforma do ensino paulista e a desobrigação do Estado. São Paulo: Xamã, 2006.

AGUIAR, M. C. C. Um olhar sobre desafios da gestão didático-pedagógica no Ensino Superior. Revista Pro.Posições, Recife: UFPE, V. 27, N. 3, 2016, p. 221-236.

BARROSO, J. Para o desenvolvimento de uma cultura de participação na escola. Lisboa: Instituto de Inovação Educacional, 1995.

BORDIGNON, G.; GRACINDO, R. V. Gestão da educação: o município e a escola. In: FERREIRA, N. S. C.; AGUIAR, M. A. da S. (Org.). Gestão da educação: impasses, perspectivas e compromissos. São Paulo: Cortez, 2000. p. 147-176

BRASIL. [Constituição (1988)]. Constituição da República Federativa do Brasil: promulgada em 5 de outubro de 1988. Disponível em:

<http://www.planalto.gov.br/ccivil_03/constituicao/constituicao.htm> Acesso em: 20 jun. 2020.

BRASIL. Lei nº 9.394 de 20 de dezembro de 1996. Lei de Diretrizes e Bases da Educação Nacional. Disponível em:

<http://www.planalto.gov.br/ccivil_03/leis/19394.htm>. Acesso em: 27 abr. 2020.

BRASIL. Lei n ${ }^{\circ}$ 13.005, de 25 de junho de 2014. Plano Nacional de Educação.

Disponível em: <http://www.planalto.gov.br/ccivil_03/_ato2011-

2014/2014/lei/113005.htm>. Acesso em: 10 maio 2020.

BRASIL, Plano diretor da reforma do aparelho do estado. Brasília, 21 set. 1995. Disponível em:

<http://www.bresserpereira.org.br/documents/mare/planodiretor/planodiretor.pdf $>$.

Acesso em 31 mar. 2020.

BRESSER-PEREIRA, L. C.; SPINK, P. Reforma do Estado e administração pública gerencial. Rio de Janeiro: Fundação Getúlio Vargas, 1998.

CÁRIA, N. P. Gestão escolar e avaliação: perspectiva e desafios contemporâneos. Campinas: Pontes Editores, 2015.

CÓSSIO, M. F. A nova gestão pública: alguns impactos nas políticas educacionais e na formação professores. Revista Educação, Porto Alegre: UFRGS, v. 41, n. 1, 2018, p. 63-73.

CURY, C. R. J. Direito à diferença: um reconhecimento legal. Revista Educação em Revista, Belo Horizonte: n. 30, p. 7-16, 1999. 
DEPONTI, C. M. et al. Estratégia para construção de indicadores para avaliação da sustentabilidade e monitoramento de sistemas. Revista Agroecologia e

Desenvolvimento Rural Sustentável. V. 3, n.4, 2002, p. 44 - 52.

HOOD, Christopher. Public management for all seasons? In: Revista Public Administration, Londres: v.69, $\mathrm{n}^{\circ}$ 01, 1991, p. 03-19.

LIBÂNEO, J. C. Organização e gestão da escola: Teoria e Prática. Goiânia: Alternativa, 2004.

LIBÂNEO, J. C. Educação escolar, políticas, estruturas e organização. São Paulo: Cortez, 2005.

LIMA, L. C. A escola como organização educativa: uma abordagem sociológica. São Paulo: Cortez, 2003.

LÜCK, H. Dimensões da gestão escolar e suas competências. Curitiba: Editora Positivo, 2009.

MOTA JÚNIOR, W. P.; MAUÉS, O. C. O Banco Mundial e as Políticas Educacionais Brasileiras. Revista Educação \& Realidade, Porto Alegre: v. 39, n. 4, 2014, p. 11371152.

OLIVEIRA, D. A. Nova gestão pública e governos democráticos-populares: contradições entre a busca da eficiência e a ampliação do direito à educação. Revista Educação e Sociedade, Campinas: v. 36, n. 132, 2015, p. 625-646.

OLIVEIRA, D. A.; DUARTE, A. W. B.; CLEMENTINO, A. M. A nova gestão pública no contexto escolar e os dilemas dos (as) diretores (as). Revista Brasileira de Política e Administração da Educação, Recife: ANPAE, v.33, n. 3, 2017, p. 707-726.

SAVIANI, D. A educação na Constituição Federal de 1988: avanços no texto e sua neutralização no contex to dos 25 anos de vigência. Revista Brasileira de Política e Administração da Educação, Recife: ANPAE, v. 29, n. 2, 2013, p. 207-221.

SHEPHERD, G.; VALENCIA, S. Modernizando a administração pública na América Latina: problemas comuns sem soluções fáceis. Revista do Serviço Público, Brasília: v.120, no 03,1996, p. 103-128.

SANDER, B. Políticas públicas e gestão democrática da educação. Revista brasileira de política e administração da educação, Porto Alegre: UFRGS, v.23, n.3, 2007, p. 421-447

ZENARDINI, I. M. S. A ideologia da pós-modernidade e a política de gestão educacional brasileira. Campinas: UNICAMP, 2006. 163f. Tese (Doutorado em Educação) - Universidade Estadual de Campinas. 